\title{
usos de las tuberías de politeno en fontanería
}

\author{
uses of polythene pipe in the plumbing trade
}

(«Buildine Industriesx, editorial, n. 825, dio. 1958, pag. 49.)

Desde que terminó la guerra, los plásticos tienen cada día más aplicactones en la construcción. Para fontanería y conducciones de agua presentan muchas y diversas ventajas, si bien éstas, por diversas circunstancias, no se conocen todavía suficientemente bien.

El politeno es el material plástico más utilizado en esta clase de trabajos. Las ventajas que implica su utilización pueden resumirse asi:

Las tuberías de politeno tienen una gran resistencia química $\mathrm{y}$, por consiguiente, son inmunes al ataque de toda clase de ácidos, álcalis y soluciones salinas; presentan unas superficies muy lisas, lo cual descarta la posibilidad de formación de costras y la adherencia de sedimentos; tampoco influyen en su comportamiento las condiciones atmosféricas; $y$, por último, contrariamente a lo que le sucede al plomo, no son atacadas por el mercurio.

Debido a su gran resistencia a la corrosión es un material ideal para utilizarlo en drenajes, puesto que ni siquiera le afectan los suelos, aunque éstos contengan cenizas y escorias.

Dichas tuberías, por no ser metálicas, son inmunes a la corrosión electrolítica y a las corrientes telúricas.

\section{RESISTENCIA AL HLELO.}

A las tuberías de politeno no les afectan las heladas repetidas y no se agrietan ni deterioran, aunque el contenido llegue a helarse. Por otra parte, sus cualidades aislantes reducen considerablemente las probabilidades de que se congelen los líquidos en su interior.

Hasta un calibre de 2 pulgadas (50,8 milímetros) los tubos de politeno son flexibles, pudiendo arrollarse en bobinas. Tal flexibilidad permite realizar las juntas de enchufe, aun cuando las tuberías se encuentren ligeramente desalineadas, sin tener que recurrir a codos o curvas. Sin embargo, esta flexibilidad no va en detrimento de la resistencia del tubo, el cual tiene un factor de seguridad adecuado, suficientemente amplio para acomodarse a cualquier régimen de funcionamiento que pueda presentarse en trabajos de ingeniería sanitaria 0 de suministros de agua.

Su dimensionado es equivalente a los de acero, lo cual facilita la colocación en obra. El tubo de 2 pulgadas $(50,8 \mathrm{~mm})$ se suministra en bobinas de 200 pies $(60 \mathrm{~m})$, de fácil manejo, pues su peso es algo más de 100 libras (45 kg). Aun cuando el material deba experimentar una manipula- 
ción violenta, llegando incluso a rozarse, no se estropea, ni siquiera en condiciones extremas.

Durante la fabricación puede pigmentarse en el color requerido, no siendo preciso pintarlo después. Su precio puede competir con el de los materiales tradicionales.

\section{ACCESORIOS DE POLITENO.}

La primera entidad que inició en Inglaterra el empleo de los plásticos resistentes a la corrosión para diversas especialidades industriales fué la Chemical Pipe \& Vessel Co. Esta firma fabrica toda clase de accesorios de fontanería $\mathrm{y}$, además, los acondiciona para su colocación en obra.

La primera instalación montada por esta Compañía se realizó en la Rothosted Experimental Station, en Harpenden, Herts, el año 1947. Desde entonces han llevado a cabo más de trescientos contratos.

El nuevo Laboratorio de Investigaciones sobre combustibles de Stevenge, Herts (actualmente en construcción), es una de las ultimas obras.

Será el primer Laboratorio cuyas tuberias de aguas residuales estarán prefabricadas en taller, las cuales se enviarán a la obra en unidades independientes $\mathrm{y}$ se unirán por los procedimientos normales. No se precisará mano de obra especializada, lo cual ređundará en amplias economías.

La firma C. P. V. facilita un amplio surtido de accesorios para las tuberías. El calibre de los accesorios se ha estudiado de modo que la unión de los tubos puede realizarse por el sistema de enchufe, quedando totalmente cerrado por medio de un cordón de soldadura.

También pueden efectuarse las uniones mediante manguitos roscados; éstos se sueldan en las extremidades de los tubos. De esta forma, aunque las construcciones sean soldadas, pueden desmontarse fácilmente, lo cual siempre es una gran ven- taja en fontaneria. Los tubos de la C. P. V. pueden roscarse utilizando terrajas y machos normales.

La firma C. P. V. facilita los materiales necesarios para montar el acoplamiento Kenley. Este evita el empleo de las juntas soldadas. Con una máquina rebordeadora normal se hacen las bridas de acoplamiento. Los casquillos para la unión pueden ser de diferentes materiales. El montaje no precisa mano de obra especializada.

\section{JUNTA ANTIFILTRANTE.}

La junta Kenley es un dispositivo muy eficaz contra las pérdidas por filtración. Aunque las uniones roscadas en los tubos de politeno se comportan muy bien bajo grandes presiones, sin embargo están supeditadas a filtraciones por capilaridad. En la junta Kenley se produce una amplia fricción entre las superficies del acoplamiento debido a la gran presión de la tuerca de unión.

El acoplamiento consta de tres partes que ajustan perfectamente. La tuerca de unión se encaja primero a mano y se aprieta definitivamente con llave, sin necesidad de ejercer gran fuerza.

La junta es sólida y resistente, quedando la parte interna del tubo en la unión lisa, sin obstáculos ni rendijas que puedan servir de puntos de acumulación de bacterias o materias extrañas.

SISTEMAS DE EVACUACION DE RESIDUALES EN POLITENO.

El primer sistema de drenaje hecho con tuberías de politeno se instaló hace nueve años en una gran fábrica de productos químicos de Midlans. Este sustituyó a otro hecho con tuberías de gres de 9 pulgadas $(23 \mathrm{~cm})$, que, debido a los asientos del terreno, tenía rotas las juntas de mortero de cemento. Esto dió lugar a que se produjeran desperfectos en las tuberías de servicio y en los cimientos del edificio, ya que los ácidos se filtraban por el terreno. 
Por no presentar filtraciones de ninguna especie las instalaciones hechas con politeno, el servicio que están dando es totalmente satisfactorio.

Los tubos de politeno se suministran en piezas de hasta 50 pies $(15 \mathrm{~m})$. Registros y sumideros se moldean o prefabrican con placas. El sistema queda soldado sin uti- lizar ningún cemento, de modo que el conjunto del sistema resulta monolítico.

Debido a la gran flexibilidad del politeno se acomoda solo a los asientos del te. rreno, sin que se Ileguen a producir grietas ni roturas.

C. S. C

\section{Refractarios especiales para la industria del cemento}

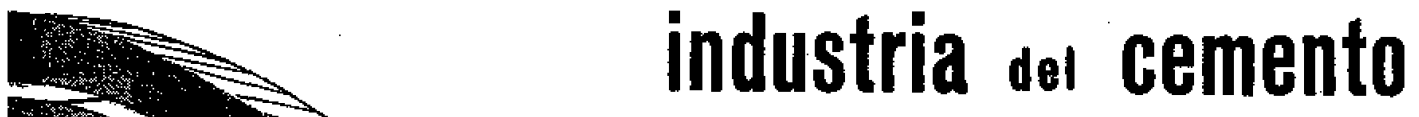

"REFRACTA"

Teléfono 33 (3 líneas)

CUART DE POBLET (Valencio)

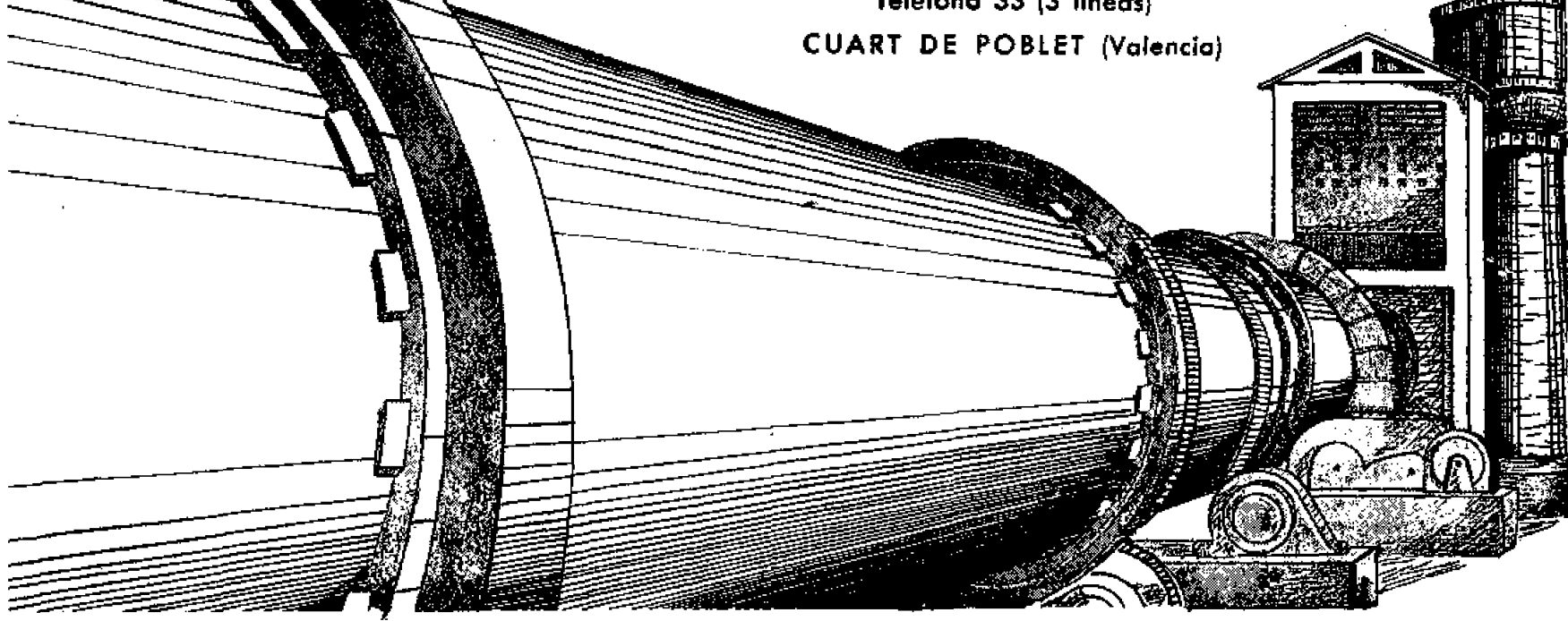

